\title{
Association of Metabolic Syndrome and Blood Pressure in Patients with Essential Hypertension
}

\section{Abhishek Kumar Chandra', Anurag Kumar², Ansuman Dalbehera ${ }^{3}$, Prakash Chandra Singh ${ }^{4}$}

${ }^{1}$ Associate Professor, Department of Medicine, Gauri Devi Institute of Medical Science, Durgapur, West Bengal;

${ }^{2}$ Assistant Professor, Traumatic and Emergency, General Surgery, AIIMS, Patna, Bihar;

${ }^{3}$ Senior Consultant Dept of Medicine, Batra Hospital Medical Research Centre, New Delhi;

${ }^{4}$ Associate Professor, Department of Paediatrics Gauri Devi Institute of Medical Science, Durgapur (WB)

Corresponding Author: Abhishek Kumar Chandra

\begin{abstract}
Objective: In Indian hypertensive patients, to investigate the prevalence and characteristics of the MS was the main objective of the present study.

Material and Method: Current study was conducted in a tertiary care OPD among 130 patients who were diagnosed with essential hypertension. Any patients who were more that 18 years of age and diagnosed with essential hypertension and willing to participate in the study were included. By routine laboratory techniques which is generally used at NABL accredited private or government testing laboratories for analysis of lipid profile total cholesterol, total triglycerides, low-density lipoprotein cholesterol and high density lipoprotein cholesterol were assayed.

Result: Average MS score were high in both the male and female group. Both male and female groups patients receives adequate blood pressure lowering treatment. In both the groups maximum patients were in ARB therapy. All parameters which are related to occurrence of metabolic syndrome like, abdominal obesity, Total Cholesterol (TC), Triglycerides (TG), Low Density Lipoprotein (LDL), fasting blood glucose (FBG) and uric acids were significantly higher in both male and female patients than the control one.

Conclusion: Current study concludes that, in Indian hypertensive patients, especially in females, metabolic syndrome was highly prevalent.
\end{abstract}

Keywords: Metabolic syndrome, metabolic risk factors, hhypertension,

\section{INTRODUCTION}

In the 20th century, cardiovascular disease (CVD) was identified as the major cause of morbidity and mortality in the developed world. In the Indian population high prevalence of diabetes and hypertension is alarming and has been attributed to metabolic syndrome. During this period there was considerable effort to understand the under lying biology of the disease and to identify the contributing risk factors. As risk factors were identified, it became apparent that more than one was often present in the same individual. Toward the end of the century, the clustering of CVD risk factors was first described, most notably the simultaneous presence of obesity, type 2 diabetes, hyperlipidemia and hypertension [1-3]. Although insulin resistance (i.e., resistance to insulin stimulated glucose uptake) as a future of type 2 diabetes was first described many years earlier ${ }^{[4]}$, hyperinsulinemia was also found to be a key feature of type 2 diabetes ${ }^{[5,6]}$, as well as hyperlipidemia ${ }^{[7-9]}$, obesity ${ }^{[10-13]}$ and hypertension ${ }^{[12-14]}$.

Despite its high prevalence, associated morbidity and increased mortality, hypertension still remains inadequately treated in the majority of 
patients. This is largely because of certain inherent problems associated with management of hypertension. The problems include on one hand, the lack of necessary concern, application and at times knowledge, on the part of the physician in question. On the other hand, the problem may be related to the lack of patient compliance.

It is important to recognize that many people exhibit a cluster of metabolic risk factors and life style factors that constitute a condition called metabolic syndrome. Characteristics features are abdominal obesity, atherogenic dyslipidemia (elevated triglycerides, small LDL particles, low HDL cholesterol), elevated blood pressure, insulin resistance (with or with our glucose intolerance) and prothrombotic and pro inflammatory states. The presence of three or more of these CV risk factors is necessary for the diagnosis of the metabolic syndrome, according to current NCEP ATP III guidelines. Nutrition and lifestyle approaches (weight reduction, increased physical activity) are the first line therapy.

Recognition of metabolic syndrome helps the clinicians to focus his attention on the need for life style therapies to reduce all metabolic risk factors currently. The growing awareness of metabolic syndrome changes the prospective from a single risk factor paradigm to multiple risk factors. This refines the evaluation of risk for both diabetes and cardio-vascular disease. Therefore, to determine the relationships between other features of the MS and hypertension is clinically important. In Indian hypertensive patients, to investigate the prevalence and characteristics of the MS was the main objective of the present study.

\section{MATERIAL AND METHOD}

Current study was conducted in a tertiary care OPD among 130 patients who were diagnosed with essential hypertension. All patients before enrolment to the study were briefed properly regarding the purpose and objective of the study and a written consent were obtained before the enrolment. Any patients who were more that 18 years of age and diagnosed with essential hypertension and willing to participate in the study were included. Any patients presented with any macro or micro vascular complication including established cardiovascular disease, any grade of heart failure, with retinal and nephrological abnormality, Obstructive sleep apnea, Hypothyroidism, hyperthyroidism, hypercalcemia, acromegaly, cognitive impairment and pregnant or lactating women were excluded from this study.

Metabolic syndrome was examined in each patient listed as per the modified ATP III version other than elevated blood pressure generally by four diagnostic criteria as mentioned bellow. Patients were considered or diagnosed as having metabolic system if there were presence of any two or more of these factors.

- High-density lipoprotein cholesterol (HDL-C) $<40 \mathrm{mg} / \mathrm{dl}$ in male and $<50$ $\mathrm{mg} / \mathrm{dl}$ in female.

- Abdominal girth $>90 \mathrm{~cm}$ in male and > $80 \mathrm{~cm}$ in female.

- Fasting plasma glucose $\geq 110 \mathrm{mg} / \mathrm{dl}$ or use of hypoglycemic agents.

- $\quad$ Fasting triglycerides $\geq 150 \mathrm{mg} / \mathrm{dl}$ and

By routine laboratory techniques which is generally used at NABL accredited private or government testing laboratories for analysis of lipid profile total cholesterol, total triglycerides, low-density lipoprotein cholesterol and high density lipoprotein cholesterol were assayed. By using standard adult arm cuff of a mercury sphygmomanometer blood pressure was measured in each arm with the subject's arm supported and at least 10 minutes after rest in sitting position.

By using SPSS 20.0 (SPSS Corp., Chicago, USA) he collected data were statistically analyzed. To examine the data, Chi-squared test and descriptive statistics were used. Throughout the study, all continuous variables were reported as mean, Standard Deviation (SD) and range. For evaluating the statistical relations between 
Abhishek Kumar Chandra et.al. Association of metabolic syndrome and blood pressure in patients with essential hypertension.

the sub groups an independent sample t- test was performed. $\mathrm{P}<0.05$ indicated that the difference was statistically significant.

\section{RESULT}

Total 130 participants participated in this trial among whom 80 patients were male and 50 patients were female (Table 1). Among total participant 80 having
Metabolic syndrome and 50 didn't have (Table 2). Table 1 depicted the demographic and characteristic details of the participants. Average MS score were high in both the male and female group. Both male and female groups patients receives adequate blood pressure lowering treatment. In both the groups maximum patients were in ARB therapy.

Table 1 Demographics and characteristics of the study population:
\begin{tabular}{|l|l|l|l|}
\hline Parameters & Male Participants (N=80) & Female Participants (N=50) & P-Value \\
\hline Age(Years) & $63.9 \pm 10.8$ & $65.7 \pm 11.9$ & $<0.001$ \\
\hline MS (\%) & $47 \%$ & $56 \%$ & 0.08 \\
\hline MS(score) & $3.2 \pm 0.8$ & $3.7 \pm 0.6$ & \\
\hline Abdominal Obesity(\%) & $58 \%$ & $78 \%$ & $<0.001$ \\
\hline Abdominal Girth (cm) & $93.4 \pm 10.1$ & $86.1 \pm 9.4$ & $<0.001$ \\
\hline TC(mg/dl) & $194.3 \pm 39.7$ & $192.8 \pm 40.1$ & 0.06 \\
\hline TG(mg/dl) & $178.8 \pm 42.9$ & $121.2 \pm 30.7$ & $<0.001$ \\
\hline LDL-c(mg/dl) & $110.2 \pm 31.3$ & $109.4 \pm 25.6$ & $<0.001$ \\
\hline HDL-c(mg/dl) & $35.8 \pm 5.2$ & $47.1 \pm 6.1$ & $<0.001$ \\
\hline Fasting glucose (mg/dl) & $125.3 \pm 29.7$ & $6.2 \pm 1.6$ & $<0.001$ \\
\hline Uric Acid (mg/dl) & $6.9 \pm 2.2$ & $8 \%$ & 0.07 \\
\hline Anti-hypertensive agent & & $8 \%$ & 0.41 \\
\hline Alpha adrenergic blocker(\%) & $7 \%$ & $24 \%$ & 0.52 \\
\hline Beta adrenergic blocker(\%) & $19 \%$ & $31 \%$ & 0.03 \\
\hline Calcium channel blockers(\%) & $42 \%$ & $42 \%$ & 0.04 \\
\hline Diuretic (\%) & $34 \%$ & $18 \%$ & 0.02 \\
\hline ACEI(\%) & $21 \%$ & $72 \%$ & 0.03 \\
\hline ARB (\%) & $25 \%$ & 0.005 \\
\hline Lipid lowering agent (Statin) & $38 \%$ & & \\
\hline
\end{tabular}

Table 2 depicts comparison of male \& female hypertensive patients with or without the metabolic syndrome. All parameters which are related to occurrence of metabolic syndrome like, abdominal obesity, Total Cholesterol (TC), Triglycerides (TG), Low Density Lipoprotein (LDL), fasting blood glucose (FBG) and uric acids were significantly higher in both male and female patients than the control one.

Table 2: Comparison of male \& female hypertensive patients with or without the metabolic syndrome.

\begin{tabular}{|c|c|c|c|c|c|c|}
\hline \multirow[t]{2}{*}{ Parameters } & \multicolumn{2}{|c|}{ Male Participants $(\mathrm{N}=\mathbf{8 0})$} & \multirow[t]{2}{*}{ P-Value } & \multicolumn{2}{|c|}{ Female Participants $(\mathrm{N}=50)$} & \multirow[t]{2}{*}{ P-Value } \\
\hline & With MS $(\mathbf{N}=50)$ & Without MS $(\mathrm{N}=30)$ & & With MS $(\mathbf{N}=30)$ & Without MS $(\mathrm{N}=20)$ & \\
\hline Age(Years) & $60.6 \pm 11.3$ & $65.2 \pm 9.3$ & $<0.001$ & $64.5 \pm 10.7$ & $66.4 \pm 12.5$ & $<0.001$ \\
\hline MS(score) & $3.8 \pm 0.9$ & $1.2 \pm 0.5$ & $<0.001$ & $3.9 \pm 0.8$ & $1.4 \pm 0.4$ & $<0.001$ \\
\hline Abdominal Obesity(\%) & $77 \%$ & $33 \%$ & $<0.001$ & $92 \%$ & $48 \%$ & $<0.001$ \\
\hline Abdominal Girth $(\mathrm{cm})$ & $97.2 \pm 11.4$ & $84.8 \pm 7.5$ & $<0.001$ & $91.4 \pm 11.2$ & $81.6 \pm 6.8$ & $<0.001$ \\
\hline $\mathrm{TC}(\mathrm{mg} / \mathrm{dl})$ & $228.8 \pm 42.6$ & $154.1 \pm 30.8$ & $<0.001$ & $209.6 \pm 48.2$ & $142.1 \pm 29.7$ & $<0.001$ \\
\hline $\mathrm{TG}(\mathrm{mg} / \mathrm{dl})$ & $221.6 \pm 54.7$ & $148.2 \pm 30.4$ & $<0.001$ & $161.2 \pm 30.7$ & $129.2 \pm 30.7$ & $<0.001$ \\
\hline LDL-c(mg/dl) & $130.5 \pm 39.8$ & $92.3 \pm 20.7$ & $<0.001$ & $121.3 \pm 27.3$ & $91.8 \pm 15.9$ & $<0.001$ \\
\hline HDL-c(mg/dl) & $32.6 \pm 5.8$ & $37.9 \pm 4.8$ & $<0.001$ & $40.3 \pm 6.7$ & $51.1 \pm 4.8$ & $<0.001$ \\
\hline Fasting glucose (mg/dl) & $132.6 \pm 31.9$ & $101.1 \pm 11.4$ & $<0.001$ & $121.4 \pm 16.3$ & $92.6 \pm 11.7$ & $<0.001$ \\
\hline Uric Acid $(\mathrm{mg} / \mathrm{dl})$ & $7.7 \pm 2.8$ & $6.1 \pm 1.7$ & $<0.001$ & $6.5 \pm 1.8$ & $5.1 \pm 1.1$ & $<0.001$ \\
\hline
\end{tabular}

\section{DISCUSSION}

Worldwide the prevalence of chronic diseases is increasing with a very rapid phase. The growing epidemic of chronic disease in many developing countries including India, disrupts health planning and overwhelms the already under resourced health care systems.
Out of 130 patients who had included in this study 80 patients were having metabolic syndrome, i.e., prevalence of metabolic syndrome is $61.5 \%$. As shown by the National Health and Nutrition Examination Survey (NHANES) carried out by Ford et al, $28 \%$ for men and $30 \%$ for women was the prevalence of metabolic 
syndrome, in US adults ${ }^{[15]}$. As compared to males $(29.9 \%)$ in patients with essential hypertension, higher prevalence of metabolic syndrome was found in females $46.6 \%$ revealed in a study conducted by $\mathrm{K}$. $\mathrm{K}$. Chandra et al ${ }^{[16]}$. Ina different angle, hypertension was linked to metabolic syndrome in women and not in men as found in a Chinese population based study conducted by Chou et al ${ }^{[17]}$. The authors of this study suggested that as compare to men, in women, role of sympathetic activity in pathogenesis of hypertension in women may be more dependent on insulin resistance. Thus, in female with essential hypertension, metabolic syndrome is more common. Even in our study MS score and abdominal obesity was higher in female as compare to men. In current study, as compare to younger age groups and male, the older age group and females had a significantly higher frequency of metabolic syndrome.

Over and above the potential risk of each risk factor in isolation, metabolic syndrome may amplify hypertension-related cardiac and renal changes ${ }^{[18]}$. The Women's Ischemia Syndrome Evaluation (WISE) study of 780 women showed that, in the subsequent 3 years, metabolic syndrome was significantly associated with a higher risk of death or major cardiovascular event ${ }^{[19]}$. People aged 30-70 years a communitybased national epidemiological health survey in Saudi Arabia also showed among females $(42 \%)$ than males $(37 \%)$ an overall adjusted frequency of metabolic syndrome (by ATP-III criteria) of $39.3 \%$, with a higher rate ${ }^{[20]}$. With hypertension waist circumference correlates strongly in women already shown in a study ${ }^{[21-23]}$.

\section{CONCLUSION}

Current study concludes that, in Indian hypertensive patients, especially in females, metabolic syndrome was highly prevalent. In line with the findings, authors strongly recumbent all clinicians who treat hypertension, routine screen to their patients to diagnose presence of metabolic syndrome and for other cardiovascular risk factors.

\section{Acknowledgement: None}

Conflict of Interest: None

\section{Source of Funding: None}

\section{Ethical Approval: Approved}

\section{REFERENCES}

1. Avogaro P, Crepaldi G, Enzi G, Tiengo A. Associazione di iperlipidemia, diabete mellito e obesità di medio grado. Alto Diabetol Lat 1967;4:36-41.

2. Haller H. Epidemiology and associated risk factors of hyperlipoproteinemia. Z Gesamte Inn Med 1977;32:124-8.

3. Singer P. Diagnosis of primary hyperlipoproteinemias. Z Gesamte Inn Med 1977;32:129-33.

4. Himsworth H. Diabetes mellitus: A differentiation into insulin sensitive and insulin insensitive types. Lancet 1936;1: 127-30.

5. Shen S-W, Reaven GM, Farquhar JW. Comparision of impedance to insulin mediated glucose uptake in normal and diabetic subjects. J Clin Invest 1970;49: 2151-60.

6. Ginsburg H, Kimmerling G, Olefesky JM, Reaven GM. Demonstration of insulin resistance in untreated adult onset diabetic subjects with fasting hyperglycemia. J Clin Invest 1975; 55:454-61.

7. Reaven GM, Lerner R, Stern M, Farquhar JW. Role of insulin in endogenous hypertriglyceridemia. J Clin Invest 1967; 46:1756-67.

8. Olefsky JM, Farquhar JW, Reaven GM. Reapprasial of the role of insulin in hypertriglyceridemia. Am J Med 1974;57: 551-60.

9. Orchard TJ, Becker DJ, Bates M, Kuller LH, Drasch AL. Plasma insulin and lipoprotein concentrations: An atherogenic association? Am J Epidemiol 1983;118:32637.

10. Olefsky JM, Kolterman OG, Scarlett JA. Insulin action and resistance in obesity and non-insulin-depandent type II diabetes melitus. Am J Physiol 1982;243:E15-E30.

11. Strn MP, Haffner SM. Body fat distribution and hyperinsulinemia as risk factors for diabetes and cardiovascular disease. Atherosclerosis 1986;6:123-30. 
Abhishek Kumar Chandra et.al. Association of metabolic syndrome and blood pressure in patients with essential hypertension.

12. Modan M, Halkin H, Almong S, Lusky A, Eshkol A, Shefi M, et al. Hyperinsulinemia: A link between hypertension, obesity and glucose intolerance. J Clin Invest 1985;75: 809-17.

13. Haffner SM, Fong D, Hazdua HP, Pugh JA, Patterson JK. Hyperinsulinemia, uppor body adiposity and cardiovascular risk factors in non-diabetes. Metabolism 1988;37:338-45.

14. Ferrannini E, Buzzigoli G, Bonadonna R, Giorico MA, Oleggini M, Graziadei L, et al. Insulin resistance in essential hypertension. N. Engl J Med 1987; 317:350-7.

15. Ford ES, Giles WH, Dietz WH. Prevalence of the metabolic syndrome among US adults. Findings from the Third National Health and Nutrition Examination Survey. JAMA. 2002;287:356-9.

16. Chandra KK, Mahotra S, Gupta M, Ubowega A, Jain S, Kumari S, et al. Prevalence of metabolic syndrome among patients with essential hypertension in the hypertension clinic of a North Indian tertiary care hospital. Indian J Cardiol. 2004;7:27-31.

17. Chen $\mathrm{CH}$, Len KC, Tsai ST, Chou P. Different association of hypertension and insulin related metabolic syndrome between men and women in 8437 non-diabetic Chinese men. Am J Hypertens. 2000;61:2937.

18. Mule $G$ et al. Influence of metabolic syndrome on hypertension related target organ damage. Journal of internal medicine, 2005, 257:503-13.

19. Peters A. The broadening domain of the metabolic syn- drome. Medscape, 27 July, 2005 (http://cme.medscape.com/ viewarticle/508282?rss, accessed 4 October 2009).

20. Kip KE et al. Clinical importance of obesity versus the meta- bolic syndrome in cardiovascular risk in women: a report from the Women's Ischemia Syndrome Evaluation (WISE) study. Circulation, 2004, 109:706.

21. Yasein N. Cardiovascular risk and anthropometric measure- ment in women attending family practice. Jordan medical journal, 2005, 39:106-11.

22. Després JP, Lemieux I, Prud'homme D. Treatment of obesity: need to focus on high risk abdominally obese patients. British medical journal, 2001, 322:716-20.

23. Braunwald E. Hypertension. In: Douglas P. Zipes, Peter Libby, Robert O. Bonow, Eugene Braunwald, eds. Braunwald's Heart Disease: a Textbook of Cardiovascular Medicine. 7th ed. Philadelphia: Saunders; 2005: 1953.

How to cite this article: Chandra AK, Kumar A, Dalbehera A et.al. Association of metabolic syndrome and blood pressure in patients with essential hypertension. International Journal of Research and Review. 2021; 8(7): 453-457. DOI: https://doi.org/10.52403/ijrr.20210763 